\title{
Patrick Menget (1942-2019)
}

\section{Philippe Erikson}

\section{(2) OpenEdition}

Journals

Édition électronique

URL : https://journals.openedition.org/jsa/16771

DOI : 10.4000/jsa. 16771

ISSN : 1957-7842

\section{Éditeur}

Société des américanistes

\section{Édition imprimée}

Date de publication : 15 juin 2019

Pagination : 7-10

ISBN : 978-2-902715-11-4

ISSN : 0037-9174

Référence électronique

Philippe Erikson, «Patrick Menget (1942-2019) », Journal de la Société des américanistes [En ligne] 105-1 | 2019, mis en ligne le 15 juin 2019, consulté le 04 septembre 2022. URL : http:// journals.openedition.org/jsa/16771 ; DOI : https://doi.org/10.4000/jsa.16771 


\title{
Patrick Menget (1942-2019)
}

\author{
Philippe ERIKSON
}

Éminent ethnologue et défenseur intransigeant de la cause des sociétés autochtones d'Amazonie, Patrick Menget nous a quittés le samedi 13 avril dernier. Il aura été membre du comité de rédaction de notre revue pendant près d'un quart de siècle (1977-2001) et vice-président de la Société des américanistes pendant plus d'une décennie (1990-2001). Son œuvre aura marqué l'américanisme tant par son volet académique que par son engagement militant: parallèlement à sa carrière universitaire, Menget fut aussi co-fondateur (en 1978) et président emblématique de la branche française de Survival International.

Enseignant à Harvard (1965-1967), à Nanterre (1970-1994), puis à l'EPHE (1995-2011), Menget a inspiré plusieurs générations d'étudiants et de collègues américanistes, dont bon nombre ont tenu à lui témoigner leur admiration dans les deux tomes d'un festschrift récemment recensé dans nos colonnes ${ }^{1}$. Il fut le premier ethnographe des Ikpeng (alias Txicão) du Brésil central, auquel il consacra en 1977 une thèse dirigée par Claude Lévi-Strauss (Menget 2001). Braconnier dans l'âme, comme il se plaisait à le dire, son travail sur ce petit groupe de langue caribe l'a également amené à s'intéresser aux populations voisines. Il put ainsi formuler des propositions plus générales sur le système politique du Haut-Xingu, qu'il fut sans doute un des premiers chercheurs à envisager comme une entité pluriethnique et plurilingue plutôt qu'un agglomérat de monades à étudier isolément (Menget 1977a, 1992). Cela est d'autant plus paradoxal que lors de sa soutenance de thèse, Claude Lévi-Strauss l'aurait justement interrogé sur l'intérêt de consacrer tant d'énergie à un groupuscule dont la population, à l'époque, dépassait à peine la cinquantaine de personnes.

Plus remarquables par leur qualité que par leur nombre absolu, les écrits de Patrick Menget se caractérisent par leur originalité, leur pouvoir de rayonnement et la vaste érudition qui les nourrit (Menget 1979, 1984, 1988, 1996). Précurseurs, ils ont largement contribué au renouveau des études amazonistes en préconisant et en mettant en œuvre une approche de la sociabilité amérindienne centrée sur la construction sociale et rituelle des corps (travaux sur la

1. Compte rendu de Diego Madi Dias dans le vol. 103-2 [2017], https://journals.openedition.org/jsa/15262. 
couvade, l'onomastique, la sexualité, les rituels...), tout en préfigurant les grandes lignes d'une analyse des sociétés concernées à l'aune de ce qu'il est aujourd'hui convenu d'appeler l'économie symbolique de la prédation (travaux sur la guerre, le rôle médiateur des captifs, les trophées...). Certains de ses textes les plus mémorables furent publiés sous les auspices de la Société des américanistes (Menget 1977b, 1985, 1993, 2008).

Outre sa production scripturale, Menget nous laisse aussi une filmographie conséquente, dont la variété thématique reflète bien toute la gamme de ses intérêts : le rituel ikpeng avec Chronique du temps sec (1976a); la résistance amérindienne face aux ravages de la déforestation avec $L$ a guerre de pacification en Amazonie (1976b); les relations intertribales au Brésil central avec Jour de fête au Xingu (1977); l'anthropologie des religions avec Xingu. Le corps et les esprits (1980); l'histoire de l'ethnologie, enfin, avec le superbe À propos de Tristes Tropiques (2003).

En apprenant le décès de Patrick, m'est revenu le souvenir d'un de ses cours où, pour illustrer l'importance de ce que Lévi-Strauss appelait la science du concret, il nous parla du pennage des urubus. Certaines de leurs plumes ont en effet la particularité d'être noires sur leur moitié inférieure - la plus visible -, tout en étant franchement blanches sur leur moitié supérieure - le plus souvent dissimulée. Sans l'observation méticuleuse de tels détails empiriques, comment saisir pleinement toute la subtilité de la mythologie amazonienne? Gestes à l'appui, le professeur charismatique qu'il était nous fit alors le récit suivant, qui ne s'éclaire, si on ose dire, qu'à la lumière de la bichromie spectaculaire de ces charognards, au demeurant bien souvent psychopompes:

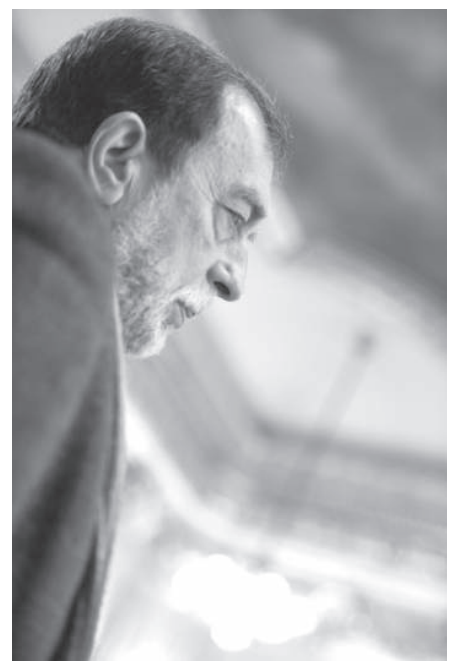

\author{
Au commencement était le jour, \\ qui dura tant que restait blanche \\ la plume qu'un démiurge \\ extrayait doucement \\ d'une calebasse d'eau. \\ Et puis soudain, \\ la nuit
}

Fig. 1 - Patrick Menget lors de la réception au Sénat du leader kayapo Raoni Metuktire le 6 décembre 2012 (C) Cliché: archives Anne-Marie Losonczy). 


\section{Références citées}

1972 « Le nouveau statut de l'Indien au Brésil » [sous le pseudonyme de Paul Crime], in Robert Jaulin (éd.), De l'ethnocide, Union générale d'édition, Paris, p. 39-69.

1977a Brésil: musiques du Haut-Xingu, livret du disque, Radio-France (Ocora, 4558517), Paris [réédité en 1993].

1977 b «Adresse et référence dans la classification sociale Txicáo », in Actes du XLII Congrès international des américanistes [Paris, 2-9 septembre 1976], Société des américanistes, Paris, vol. II, p. 323-339.

1979 «Temps de naître, temps d'être: la couvade », in Michel Izard et Pierre Smith (éd.), La fonction symbolique. Essais d'anthropologie, Gallimard, Paris, p. 245-264.

1984 « Delights and danger: notes on sexuality in the Upper Xingu », in Kenneth Kensinger (éd.), Sexual ideologies in Lowland South America, Bennington College (Working Papers on South American Indians, 5), Vermont, p. 4-11.

1985 « Jalons pour une étude comparative. Introduction du dossier: "Guerre, sociétés et vision du monde dans les Basses Terres de l'Amérique du Sud" », Journal de la Société des américanistes, 71, p. 131-141.

1988 « Note sur l'adoption chez les Txicáo du Brésil central », Anthropologie et Sociétés, 12 (2), p. 63-72.

1992 «Les frontières de la chefferie. Remarques sur le système politique du HautXingu (Brésil) », L'Homme, 122-124 (2-4), p. 61-78.

1993 «Le propre du nom. Remarques sur l'onomastique Txicáo », Journal de la Société des américanistes, 79, p. 21-31.

1996 «De l'usage des trophées en Amérique du Sud. Esquisse d'une comparaison entre les pratiques nivacle (Paraguay) et mundurucu (Brésil) », in Destins de meurtriers. Systèmes de pensée en Afrique noire, 14, p. 127-143.

2001 Em nome dos outros. Classificação das relações sociais entre os Txicáo do Alto Xingu, Museu Nacional de Etnologia/Assírio \& Alvim, Lisbonne.

2008 «Kinship theory after Lévi-Strauss' elementary structures », Journal de la Société des américanistes, 94 (2), p. 29-37.

\section{Filmographie}

1976a Chronique du temps sec (l'initiation chez les Txicáo), film 16 mm, couleurs, son optique, 73 minutes, en collaboration avec Yves Billon et Jean-François Schiano et avec le concours du Serddav (Ivry), diffusé par la Sept (Arte).

1976b La guerre de pacification en Amazonie, film 16 mm, en collaboration avec Yves Billon et Jean-François Schiano, 90 minutes, Les Films du Village, Zaradoc Films.

1977 Jour de fête au Xingu (le Kuarup et ses visiteurs à Kamayura), film 16 mm, couleurs, son optique, 46 minutes, en collaboration avec Yves Billon et JeanFrançois Schiano, Les Films du Village, Zaradoc Films.

$1980 X i n g u$. Le corps et les esprits, réalisation Mari Corrêa, rôle de conseiller scientifique Patrick Menget, 60 minutes, diffusé par Zarafa films.

2003 A propos de Tristes Tropiques, film $16 \mathrm{~mm}$ et vidéo, 46 minutes, en collaboration avec Jean-Pierre Beaurenaut et Jorge Bodanzky, co-produit par la Sept et les Films du Village, diffusé par la Sept (Arte)/Zarafa Films. 


\section{Annexe}

\section{Post-scriptum}

Grand amateur de romans policiers et d'espionnage, de Tony Hillerman à John Le Carré, Patrick était fasciné par tout ce qui touchait au secret, aux enquêtes et à la clandestinité. Faute de données disponibles sur les Ikpeng, le projet de thèse qu'il rédigea à Harvard portait essentiellement sur les Kuikuru, mieux documentés à l'époque grâce aux travaux de Gertrude Dole et Robert Carneiro. Il comptait, pour se couvrir, sur une note de bas de page précisant qu'il n'excluait pas, si l'opportunité s'en présentait, de se consacrer aux Txicáo récemment contactés. Un des faits d'armes les plus marquants que Patrick se plaisait à raconter était d'avoir convaincu un gestionnaire de Nanterre que « corruption de fonctionnaire brésilien » était un motif suffisant pour justifier, sur ses notes de frais, de l'achat d'une caisse de whiskey! Sans doute cet attrait pour les chemins de traverse et pour les pirouettes administratives explique-il pourquoi - bien qu'il ait toujours été pour moi un modèle, un maître et un mentor Patrick n'aura finalement jamais dirigé mes propres recherches que de manière officieuse, dans un rôle de conseiller de l'ombre qui, au bout du compte, lui seyait à merveille. Mon « crypto-directeur » de thèse et de HDR racontait aussi volontiers la campagne menée, en compagnie d'autres étudiants engagés, pour sauver Régis Debray d'une exécution sommaire dans les geôles boliviennes après la capture de Che Guevara. Au moment de la guerre d'Algérie, Patrick avait courageusement participé à un réseau de convoyage d'insoumis qui fuyaient le pays pour éviter la conscription. On s'étonnera moins, dès lors, qu'un de ses premiers écrits parut en 1972 sous le pseudonyme de " Paul Crime». Romanesque et pudique à la fois, le récit qu'il faisait de la maladie qui l'affecta les dernières années de sa vie reflète bien ce goût profond pour l'aventure et le mystère. Patrick se disait atteint d'une affection pulmonaire contractée, jadis, en Amazonie, en mangeant de la viande de tatou. Histoire, hélas, trop belle pour être vraie ou trop vraie pour être belle. 